\title{
Infrequent loss of heterozygosity of APC/MCC and DCC genes in gastric cancer showing DNA microsatellite instability
}

\begin{abstract}
Dian-Chun Fang, Jeremy R Jass, Dong-Xu Wang, Xiao-Dong Zhou, Yuan-Hui Luo, Joanne Young
\end{abstract}

Department of

Gastroenterology, 3rd Military Medical

University, Southwest Hospital, Chongqing,

China

D-C Fang

D-X Wang

X-D Zhou

Y-H Luo

Department of Pathology, University of Queensland Medical School, Herston Road, Queensland 4006, Australia

J R Jass

Glaxo Conjoint Gastroenterology Laboratory, Bancroft Centre, Royal Brisbane Hospital, Herston, Queensland, Australia

J Young

Correspondence to: Professor Jass. email:

j.jass@mailbox.uq.edu.au

Accepted for publication 1 April 1999

\begin{abstract}
Aim-To investigate the role of DNA microsatellite instability (MSI) in gastric carcinogenesis by studying associations between MSI status, clinicopathological features, and loss of genetic loci.

Methods-Six microsatellite loci and loss of heterozygosity at APC, DCC, and MCC were analysed by polymerase chain reaction based methods in 53 cases of advanced gastric cancer.

Results-MSI was observed in $32.1 \%$ of gastric carcinomas (17/53) and $20 \%$ of foci of intestinal metaplasia (3/15). Seven gastric carcinomas $(13.7 \%)$ were MSI-high (MSI-H) (three loci or more) and 10 (18.9\%) were MSI-low (MSI-L) (one or two loci). The frequency of MSI-H was higher in intestinal $(25.0 \%)$ than in diffuse carcinomas $(3.7 \%)(p<0.05)$. None of the MSI-H tumours showed loss of heterozygosity at APC, MCC, or DCC loci.

Conclusions-MSI may have an important and early role in a subset of gastric cancers, particularly the intestinal type. The MSI-H subset of gastric cancer has features in common with its colorectal counterpart, whereas MSI-L and microsatellite stable cancers appear to develop through the loss of heterozygosity pathway.

(F Clin Pathol 1999;52:504-508)
\end{abstract}

Keywords: gastric cancer; loss of heterozygosity; microsatellite instability

Both colorectal $^{12}$ and gastric carcinomas ${ }^{34}$ may show DNA microsatellite instability (MSI). In the case of colorectal cancer, MSI status is correlated with a range of clinical, pathological, and molecular variables. It is agreed that about $20 \%$ of colorectal cancers are MSI. Of these one half are MSI-high (MSI-H), in which instability is found in at least $40 \%$ of loci, and the remainder are MSI-low (MSI-L). ${ }^{5-8}$ Although a generic "suppressor" pathway for the molecular pathogenesis of colorectal cancer is well established, ${ }^{9}$ MSI-H cancers are distinguished by a low frequency of mutation of the adenomatous polyposis coli (APC), K-ras, and p53 genes and infrequent loss of heterozygosity at $5 \mathrm{q}, 17 \mathrm{p}$, and $18 \mathrm{q} .^{5}$ Other genes including transforming growth factor $\beta$ type II receptor (TGF $\beta$ IIR), insulinlike growth factor receptor 2 (IGFR2), and BAX are associated with the "mutator" pathway. ${ }^{8}$ Despite displaying a mild mutator phenotype, MSI-L colorectal cancers appear to evolve through the classical "suppressor" pathway. $^{58}$

Less is known of the molecular evolution of gastric cancer, though well differentiated or intestinal type gastric cancer share genetic profiles with colorectal cancer. ${ }^{10}$ Different genetic mechanisms apply to poorly differentiated or diffuse type carcinomas, for example loss of heterozygosity at $7 \mathrm{q}$, cadherin mutation, or loss and amplification of K-sam and c-met. ${ }^{10}$ MSI has been described in both well differentiated and poorly differentiated types of gastric cancer. Some reports have emphasised an association with poorly differentiated gastric cancer. $^{3}$ Others correlate MSI with intestinal metaplasia, adenoma, and intestinal-type or well differentiated gastric cancer. ${ }^{11}{ }^{12}$ These discrepancies relate, at least in part, to the need to distinguish MSI-H and MSI-L, as in colorectal cancer. ${ }^{1314}$ Early studies from Japan reported high frequencies of MSI in gastric cancer $(39 \%$ and $33 \%),{ }^{3}$ but the incidence of MSI-H gastric cancer lies between $4 \%$ and $15 \%$, similar to that of colorectal cancer. ${ }^{12}{ }^{15-18}$ There is also evidence that gastric MSI-H cancers share features with their colorectal counterparts, including infiltration by $\mathrm{T}$ lymphocytes and improved prognosis ${ }^{19}$ and mutation of TGF $\beta$ RII. ${ }^{20}{ }^{21}$ It seems, however, that the MSI-L phenotype occurs with greater frequency in gastric than colorectal cancer. For example, using a panel of 138 microsatellite markers, Gleeson et al found MSI-L in $84 \%$ of cancers arising in the gastric cardia. ${ }^{22}$

The aim of this preliminary study was to investigate the frequency of loss of heterozygosity at loci in $5 \mathrm{q}$ and $18 \mathrm{q}$ in a series of gastric cancers stratified as microsatellite stable (MSS), MSI-L, and MSI-H.

\section{Methods}

Fifty three gastric cancers and corresponding normal tissue were obtained from patients with surgically resected gastric carcinoma in Southwest Hospital, Chongqing, People's Republic China. Thirty nine men and fourteen women with an age range of 28 to 74 years were included (mean age of 53 years at diagnosis). In all cases, one half of each tissue sample was frozen in liquid nitrogen and stored at $-80^{\circ} \mathrm{C}$ until analysed and the other half was submitted for histological examination. Fifteen of these specimens contained adjacent foci of intestinal metaplasia, which were also collected. DNA was extracted using standard protocols. Can- 


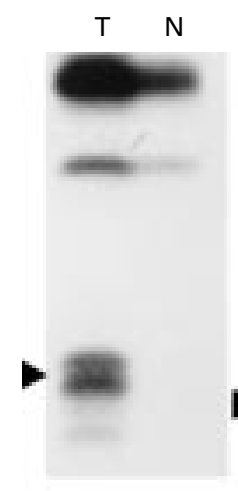

D5S409

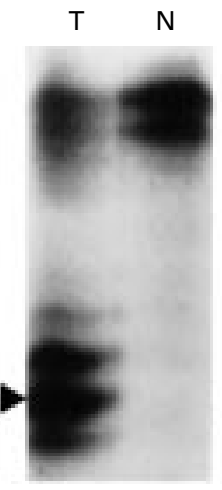

D5S82

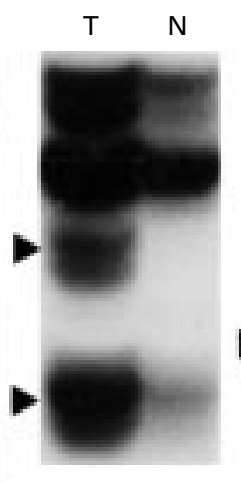

D17S261

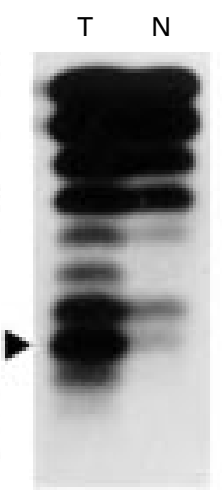

D17S799

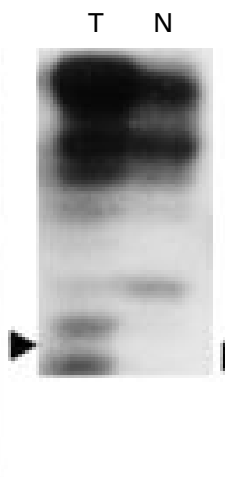

TCF-2
T N

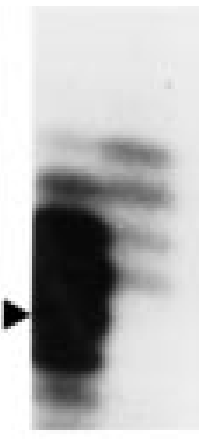

D18S34

Figure 1 MSI in gastric carcinoma using six microsatellite loci (D5S82, D5S409, D17S261, D17S799, TCF-2, and D18S34). N, normal DNA; T, tumour DNA; arrowheads, new bands.

cers were classified as intestinal or diffuse according to Laurén. ${ }^{23}$

Six well characterised loci in $5 \mathrm{q}, 17 \mathrm{p}$, and $18 \mathrm{q}$ containing dinucleotide repeat sequences were studied. D5S409, D5S82, D17S261, D17S799, TCF-2, and D18S34 primers ${ }^{24-27}$ were used to amplify the repeat and short flanking sequences in template DNA using polymerase chain reaction (PCR). PCR was performed in $20 \mu \mathrm{l}$ of reaction mixture containing $10 \mathrm{mmol} /$ litre Tris- $\mathrm{HCl}(\mathrm{pH} 8.3)$, $50 \mathrm{mmol} /$ litre $\mathrm{KCl}, 1.5 \mathrm{mmol} /$ litre $\mathrm{MgCl}_{2}, 200$ $\mu \mathrm{mol} /$ litre each deoxynucleotide triphosphate except deoxycytidine triphosphate (dCTP), 80 $\mu \mathrm{mol} /$ litre dCTP, $1 \mu \mathrm{Ci}\left(\alpha-{ }^{32} \mathrm{P}\right) \mathrm{dCTP}, 0.5 \mu \mathrm{mol} /$ litre of each primer, 0.75 unit Ampli Taq polymerase (Perkin-Elmer Cetus), and $100 \mathrm{ng}$ genomic DNA. The reaction was carried out in a thermal cycler at $94^{\circ} \mathrm{C}$ for 40 seconds, $55-62^{\circ} \mathrm{C}$ for 40 seconds, and $72^{\circ} \mathrm{C}$ for $40 \mathrm{sec}-$ onds, for 35 cycles, with an initial denaturation step of $94^{\circ} \mathrm{C}$ for five minutes and a final extension step of $72^{\circ} \mathrm{C}$ for 10 minutes. Samples were then separated in $6 \%$ polyacrylamide, $7 \mathrm{M}$ urea denaturing DNA sequencing gel, and visualised by autoradiography. The autoradiogram

Table 1 Relation of microsatellite instability (MSI) status with clinopathological variables

\begin{tabular}{|c|c|c|c|c|}
\hline Variable & $n$ & $\begin{array}{l}M S S \\
(n=36)\end{array}$ & $\begin{array}{l}M S I-L \\
(n=10)\end{array}$ & $\begin{array}{l}M S I-H \\
(n=7)\end{array}$ \\
\hline \multicolumn{5}{|l|}{ Age } \\
\hline$<40$ years & 11 & 6 & 3 & 2 \\
\hline$>40$ years & 42 & 30 & 7 & 5 \\
\hline \multicolumn{5}{|l|}{ Sex } \\
\hline Male & 39 & 28 & 7 & 4 \\
\hline Female & 14 & 8 & 3 & 3 \\
\hline \multicolumn{5}{|l|}{ Location } \\
\hline Antrum & 32 & 22 & 6 & 4 \\
\hline Body & 15 & 10 & 3 & 1 \\
\hline Cardia & 6 & 4 & 1 & 1 \\
\hline \multicolumn{5}{|l|}{ Size } \\
\hline$<5 \mathrm{~cm}$ & 21 & 14 & 4 & 3 \\
\hline$>5 \mathrm{~cm}$ & 32 & 22 & 6 & 4 \\
\hline \multicolumn{5}{|l|}{ Type } \\
\hline Intestinal & 24 & 13 & 5 & $6^{\star}$ \\
\hline Diffuse & 27 & 22 & 4 & 1 \\
\hline Unclassified & 2 & 1 & 1 & 0 \\
\hline \multicolumn{5}{|l|}{ Invasion } \\
\hline Within the wall & 23 & 16 & 3 & 4 \\
\hline Invading serosa & 30 & 20 & 7 & 3 \\
\hline \multicolumn{5}{|l|}{ Lymph node spread } \\
\hline Absent & 22 & 16 & 4 & 2 \\
\hline Present & 31 & 20 & 6 & 5 \\
\hline
\end{tabular}

${ }^{\star} \mathrm{p}<0.05$. analysis of tumour and control patterns was carried out by two independent observers. Both observers had to identify band shifts in order to diagnose instability at a particular locus. A band shift was defined as the presence of bands in PCR products of sample tissue that were not visible in corresponding constitutional DNA.

The APC, mutated in colon cancer (MCC), and deleted in colon cancer (DCC) genes were investigated for loss of heterozygosity, and PCR was carried out as described by others. ${ }^{28}{ }^{29}$ The priming regions were located within the genes APC, MCC, and DCC at polymorphic sequences: an Rsa 1 RFLP in exon 11 of APC, a 14 base pair (bp) insertion/deletion polymorphism in exon 10 of MCC, and at Msp1 RFLP sites in VNTR, M2, and M3 of DCC. ${ }^{28}{ }^{29}$ The intragenic locations were selected to provide specific and sensitive evidence of loss. Annealing temperature, extension time, and the number of amplification cycles were optimised for each primer set. After amplification, PCR products were digested with appropriate restriction enzymes (for RFLP) or not (for variable numbers of tandem repeats) and electrophoresed on $3 \%$ agarose gels or $8 \%$ polyacrylamide gels, which were stained with ethidium bromide and photographed under ultraviolet light. Loss of heterozygosity was defined as a visible change in allele to allele ratio in the DNA relative to the ratio in corresponding normal DNA.

Analyses were carried out using the $\chi^{2}$ test with Yates' correction. A p value of $<0.05$ was considered significant.

\section{Results}

Seventeen of 53 gastric cancers $(32.1 \%)$ showed evidence of MSI. Comparison of normal and tumour tissue DNA samples showed a shift in the latter, indicating an alteration in the microsatellite site (fig 1). Based on the number of mutated MSI markers in each tumour, carcinomas were divided into three groups: MSI-H, showing MSI in three or more loci (7), MSI-L, showing MSI in one or two loci (10), and microsatellite stable (MSS) (36). 
A

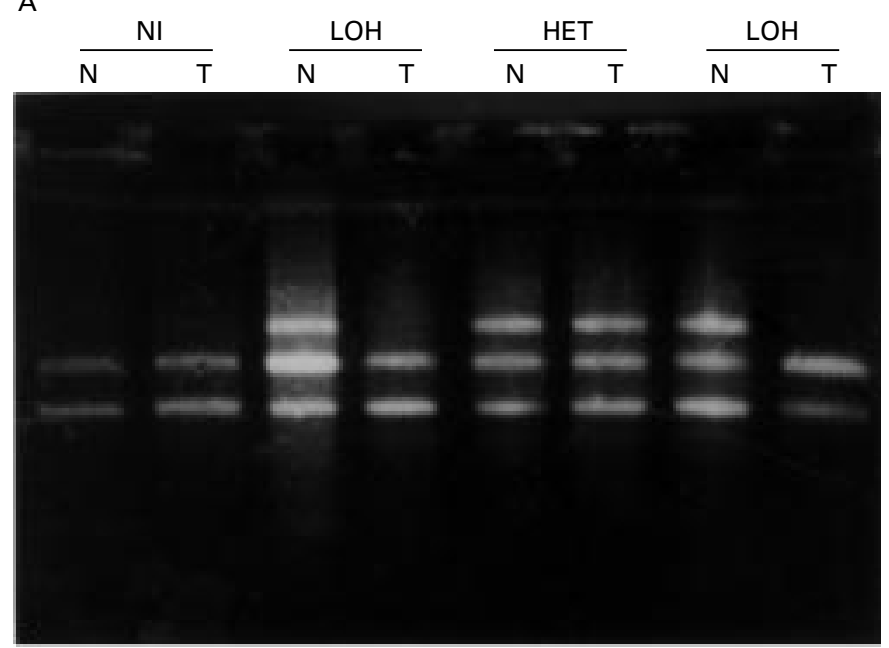

B

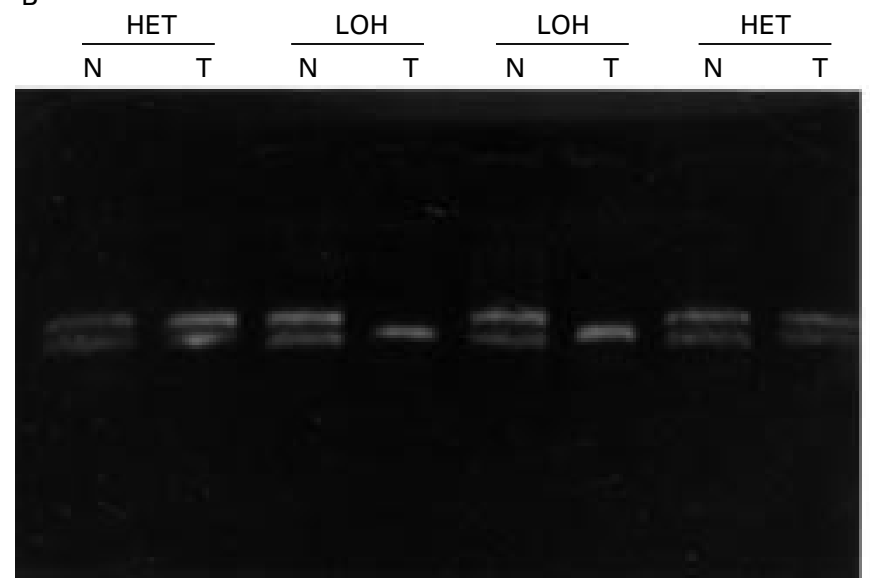

$93 \mathrm{bp}$

$79 \mathrm{bp}$

Figure 2 Loss of heterozygosity at APC and MCC in four gastric cancers. (A) Rsa 1 RFLP in APC exon 11. Loss of 133 base pair (bp) allele is seen in tumour DNA. (B) $A$ $14 \mathrm{bp}$ insertion/deletion polymorphism in MCC exon 10 gives rise to a 93 or $79 \mathrm{bp}$ allele. Loss of the $93 \mathrm{bp}$ allele is seen in the tumour.

Clinicopathological characteristics of MSI-H cases were compared with those of cases that were MSS or MSI-L (table 1). An association of MSI-H with intestinal histological type was found $(p<0.05)$, whereas no significant correlation was found between MSI-H and age at diagnosis, sex, tumour location, size, depth of invasion, or lymph node metastasis.

Three of 15 samples of intestinal metaplasia (20\%) showed MSI at a single locus (MSI-L), as well as in the corresponding cancer tissue. This was seen only in cases of MSI-L cancers. Identical and possibly sequentially related micosatellite alterations were observed in the cancer tissue and adjacent intestinal metaplasia, two cases at locus D5S82 and the other case at D18S34.

Examples of loss of heterozygosity at APC and MCC are shown in fig 2. The loss of heterozygosity frequencies for APC, MCC, and DCC were 10 of $36(27.8 \%)$, nine of 29 (31.0\%), and 19 of $51(37.3 \%)$ gastric cancers respectively. The associations of loss of heterozygosity and MSI status are shown in table 2. All tumours that showed loss of heterozygosity
Table 2 Relation of microsatellite instability (MSI) status with loss of heterozygosity ( $\mathrm{LOH})$

\begin{tabular}{lllll}
\hline & $\begin{array}{l}\text { MSS } \\
(n=36)\end{array}$ & $\begin{array}{l}\text { MSI-L } \\
(n=10)\end{array}$ & $\begin{array}{l}M S I-H \\
(n=7)\end{array}$ & p Valuet \\
\hline LOH & & & & \\
APC & $8 / 24^{\star}$ & $2 / 7$ & $0 / 5$ & 0.37 \\
MCC & $7 / 20^{\star}$ & $2 / 5$ & $0 / 4$ & 0.38 \\
DCC & $15 / 35^{\star}$ & $4 / 10$ & $0 / 6$ & 0.13 \\
\hline
\end{tabular}

${ }^{\star}$ Informative.

$+\chi^{2}$ test with Yates correction.

APC, adenomatous polyposis coli gene; DCC, deleted in colon cancer gene; MCC, mutated in colon cancer gene; MSS, microsatellite stable

in APC, MCC, and DCC belonged to the MSS and MSI-low groups and none of the MSI-high tumours showed loss of heterozygosity. The numbers are too small to reach statistical significance, however.

\section{Discussion}

In this study $32.1 \%$ of 53 sporadic gastric cancers had MSI in at least one locus, a frequency falling within the wide reported range. $^{3} 412$ 15-18 22 However, the frequency of MSI-H was only $13.7 \%$, which is similar to figure reported by others in both gastric ${ }^{12-18}$ and colorectal cancer. ${ }^{5-8}$

Gastric adenocarcinoma usually affects patients older than 50 years and is uncommon in subjects younger than 40 years. Tumours occurring in young patients (under 40 years of age) account for less than $10 \%$ of all cases. ${ }^{30} 31$ It has been suggested that early onset gastric carcinomas are more likely to have a genetic basis than those occurring in older patients. ${ }^{30} 32$ Hayden et al investigated a series of 10 British gastric carcinoma patients aged 19 to 39 years using a panel of 12 microsatellite loci and found no evidence of MSI. ${ }^{33}$ In the present study, we divided gastric cancers into two groups according to age and found no difference in MSI frequency in patients aged under 40 years and in those over 40 years. These results contrast with the situation in colorectal cancer in which $58 \%$ of patients without a family history of cancer aged under 35 years show evidence of $\mathrm{MSI}^{32}$ and cast doubt on the role of the mutator phenotype as an important mechanism in the development of early onset gastric cancer.

Histologically, gastric cancer can be classified into two subtypes: intestinal and diffuse. ${ }^{23}$ The former is often accompanied by widespread intestinal metaplasia in the vicinity of the tumour, and is generally believed to arise through a multistage process involving chronic gastritis and intestinal metaplasia. ${ }^{34}$ These morphological changes from normal gastric epithelium may occur sequentially as a result of exogenous and endogenous factors that cause genetic alterations. ${ }^{34}$ Some of these lesionsincluding p53 mutation and $17 \mathrm{p}, 5 \mathrm{q}$, and $18 \mathrm{q}$ allelic loss, which are common in colorectal tumours-are more frequent in intestinal than in diffuse gastric carcinoma. ${ }^{10}{ }^{35}$ Previous observations also indicate that the MSI phenotype tends to be more frequent in tumours of intestinal than diffuse type. ${ }^{11}{ }^{12}{ }^{36}$ These findings are in keeping with the suggestion that 
MSI phenotype is an important and early event in gastric carcinogenesis of intestinal type. The fact that instability was detectable at the stage of intestinal metaplasia supports this interpretation.

Interestingly, an identical and possibly sequential alteration was observed in the cancer samples and the adjacent metaplastic mucosa in three cases, supporting the concept of tumour development from intestinal metaplasia. This observation related to MSI-L cancers with a single mutated locus only. MSI was not detected in intestinal metaplasia surrounding MSI-H gastric cancers. The significance of low levels of MSI is currently unknown. The fact that the MSI-L phenotype in intestinal metaplasia implicated only D5S82 and D18S34 and occurred in adjacent intestinal type cancers in three instances suggests that these loci may serve as biomarkers for genetically unstable variants of intestinal metaplasia.

Attempts have been made to correlate the presence of MSI with other clinicopathological features in gastric carcinoma. Some have reported an association between MSI and expanding growth pattern, absent or minimal desmoplastic response, abundant lymphoid infiltration, low DNA content, relatively low frequency of lymph node metastasis, and improved prognosis. ${ }^{19}{ }^{37}$ Another study showed no survival advantage at five and eight years of follow up in patients stratified according to MSI status, even when corrected for stage distribution. ${ }^{38}$ In the present study, we did not observe a correlation between MSI status and tumour location, size, depth of invasion, or lymph node metastasis, indicating a limited role for MSI in predicting prognosis of gastric cancer. However, further follow up of a larger number of patients is required.

None of the MSI-high tumours showed loss of heterozygosity at APC, MCC, and DCC loci, an observation that parallels studies in colorectal cancer ${ }^{59}$ and suggests that MSI-H gastric tumours differ from MSS and MSI-L tumours in their mode of molecular evolution. Again, the findings need to be confirmed in a larger series.

\section{CONCLUSIONS}

Genetic instability underlies the multistep evolution of gastric cancer. Gastric carcinomas can be classified three groups: MSS, MSI-L, and MSI-H. The MSI-H tumours appear to share features with their colorectal counterparts, exemplified in this study by the low frequency of loss of heterozygosity at $5 \mathrm{q}$ and $18 \mathrm{q}$. Widespread MSI may play an important and early role in the evolution of a subset of intestinal type gastric carcinomas. The biological significance of MSI-L remains unclear.

This work was supported by the National Funds of Natural Science of China, No 39670347 . We thank Lynne Reid for photographic assistance and Brenda Mason for secretarial support.

1 Ionov Y, Peinado MA, Malkhosyan S, et al. Ubiquitous somatic mutations in simple repeated sequences reveal a new mechanism of colonic carcinogenesis. Nature 1993;363:558-61.
2 Thibodeau SN, Bren G, Schaid D. Microsatellite instability in cancer of the proximal colon. Science 1993;260:816-19. 3 Han HJ, Yanagisawa A, Kato Y, et al. Genetic instability in pancreatic cancer and poorly differentiated type of gastric ancer. Cancer Res 1993;53:5087-9.

4 Chong JM, Fukayama M, Hayashi Y, et al. Microsatellite instability in the progression of gastric carcinoma. Cancer Res 1994;54:4595-7.

5 Konishi M, Kikuchi-Yanoshita R, Tanaka K, et al. Molecular nature of colon tumours in hereditary nonpolyposis colon cancer, familial polyposis, and sporadic colon cancer. Gastroenterology 1996;111:307-17.

6 Dietmaier W, Wallinger S, Bocker $\mathrm{T}$, et al. Diagnostic microsatellite instability: Definition and correlation with mismatch repair protein expression. Cancer Res 1997;57: mismatch

7 Thibodeau SN, French AJ, Cunningham JM, et al. Microsatellite instability in colorectal cancer: different mutator phenotypes and the principal involvement of hMLH1. Cancer Res 1998;58:1713-18.

8 Jass JR, Do K-A, Simms LA, et al. Morphology of sporadic colorectal cancer with DNA replication errors. Gut 1998;42:673-9.

9 Vogelstein B, Fearon ER, Hamilton SR, et al. Genetic alterations during colorectal tumour development. $N$ Engl $\mathcal{F}$ Med 1988;319:525-32.

10 Tahara E, Semba S, Tahara H. Molecular biological observations in gastric cancer. Semin Oncol 1996;23:30715.

11 Semba S, Yokozaki H, Yamamoto S, et al. Microsatellite instability in precancerous lesions and adenocarcinomas of the stomach. Cancer 1996;77:1620-7.

12 Keller G, Rotter M, Vogelsang H, et al. Microsatellite instability in adenocarcinomas of the upper gastrointestinal tract. Relation to clinicopathological data and family history. Am F Pathol 1995;147:593-600.

13 Hayden JD, Martin IG, Cawkwell L, et al. The role of microsatellite instability in gastric carcinoma. Gut 1998;42: $300-3$.

14 Boland CR, Thibodeau SN, Hamilton SR, et al. A National Cancer Institute Workshop on microsatellite instability for cancer detection and familial predisposition: Development of international criteria for the determination of microsat5248-57.

15 Nakashima $\mathrm{H}$, Inoue $\mathrm{H}$, Mori $\mathrm{M}$, et al. Microsatellite instability in Japanese gastric cancer. Cancer 1995;75:1503-7.

16 Toh Y, Oki E, Oda S, et al. An integrated microsatellite length analysis using an automated fluorescent DNA sequencer. Cancer Res 1996;56:2688-91.

17 Schneider B, Pulitzer DR, Brown RD, et al. Allelic imbalance in gastric cancer: an affected site on chromosome arm 3p. Genes Chromosomes Cancer 1995;13:263-71.

18 Strickler JG, Zheng J, Shu QP, et al. p53 mutations and microsatellite instability in sporadic gastric cancer: when guardians fail. Cancer Res 1994;54:4750-5.

19 Seruca R, Santos NR, David L, et al. Sporadic gastric carcinomas with microsatellite instability display a particular nomas with microsatellite instability display a particu

20 Myeroff L, Parsons R, Kim S-J, et al. A transforming growth factor $\beta$ receptor type II gene mutation common in colon and gastric but rare in endometrial cancers with microsatellite instability. Cancer Res 1996;55:5545-7.

21 Shitara Y, Yokozaki H, Yasui W, et al. Mutation of the transforming growth factor- $\beta$ type II receptor gene is a rare event in human sporadic gastric carcinomas. Int $\mathcal{f}$ Oncol 1998;12:1061-5.

22 Gleeson CM, Sloan JM, McGuigan JA, et al. Widespread microsatellite instability occurs infrequently in adenocarcinoma of the gastric cardia. Oncogene 1996;12:1653-62.

23 Laurén P. The two main histological types of gastric cancer; diffuse and so-called intestinal type carcinoma. Acta Pathol Microbiol Scand 1965;64:31-49.

24 Breukel C, Tops C, VanLeeuwen C, et al. CA repeat polymorphism at D5S82 locus, proximal to adenomatous polyposis coli (APC). Nucleic Acids Res 1991;19:5804.

25 Tamura G, Sakata K, Maesawa C, et al. Microsatellite alterations in adenoma and differentiated adenocarcinoma of the stomach. Cancer Res 1995;55:1933-6.

26 Weber JL, Kwitek AE, May PE, et al. Dinucleotide repeat polymorphisms at D17S250 and D17S261 loci. Nucleic Acids Res 1990;18:4640.

27 Weber JL, May PE. Dinucleotide repeat polymorphism at D18S34 locus. Nucleic Acids Res 1990;18:3431.

28 Gao X, Honn KV, Grignon D, et al. Frequent loss of expression and loss of heterozygosity of the putative tumour supsion and loss of heterozygosity of the putative tumour sup-
pressor gene DCC in prostatic carcinomas. Cancer Res 1993;53:2723-7.

29 Tamura G, Maesawa C, Suzuki Y, et al. Primary gastric carcinoma cells frequently lose heterozygosity at the APC and MCC genetic loci. Fpn f Cancer Res 1993;84:1015-18.

30 Fujimoto S, Takahashi $M$, Ohkubo $\mathrm{H}$, et al. Comparative clinicopathological features of early gastric cancer in young and older patients. Surgery 1994;115:516-20.

31 Mecklin JP, Nording S, Saario I. Carcinoma of the stomach and its heredity in young patients. Scand $\mathcal{f}$ Gastroenterol 1988;23:307-11.

32 Liu B, Farrington SM, Petersen GM, et al. Genetic instability occurs in the majority of young patients with colorectal ity occurs in the majority of young

33 Hayden JD, Cawkwell L, Sue-Ling H, et al. Assessment of microsatellite alterations in young patients with gastric adenocarcinoma. Cancer 1997;79:684-7. 
34 Correa P. Human gastric carcinogenesis: a multistep and multifactorial process Cancer Res 1992:52:6735-40.

35 Sano T, Tsujino T, Yoshida K, et al. Frequent loss of heterozygosity on chromosomes $1 \mathrm{q}, 5 \mathrm{q}$, and $17 \mathrm{p}$ in human gastric carcinomas. Cancer Res 1991:51:2926-31.

36 Buonsanti G, Calistri D, Padovan L, et al. Microsatellite instability in intestinal- and diffuse-type gastric carcinoma. f Pathol 1997;182:167-73.

37 Dos Santos NR, Seruca R, Constancia M, et al. Microsatellite instability at multiple loci in gastric carcinoma: clinico- pathologic implications and prognosis. Gastroenterology 1996:110:38-44.

38 Ottini L, Palli D, Falchetti M, et al. Microsatellite instability in gastric cancer is associated with tumour location and family history in a high risk population from Tuscany. Cancer Res 1997;57:4523-9.

39 Yamamoto $\mathrm{H}$, Itoh $\mathrm{F}$, Kusano $\mathrm{M}$, et al. Infrequent inactivation of DCC gene in replication error-positive colorectal cancers. Biol Biophys Res Commun 1998;244:204-9.

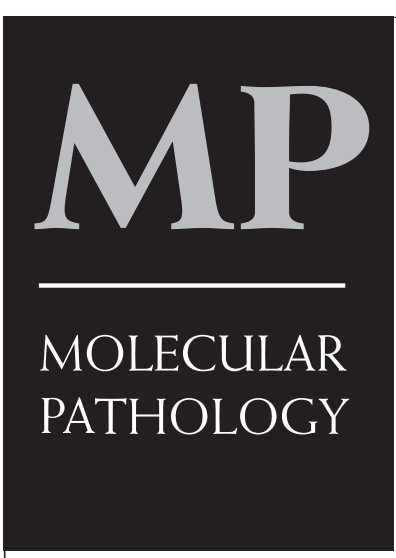

Contents

\section{June 1999 Vol 52 No 3}

\section{Reviews}

111 Demystified ... Gene knockouts $\mathcal{F}$ P Iredale

117 Demystified ... DNA nucleotide sequencing $\mathcal{F} S$ Randhawa, $A \mathcal{F}$ Easton

125 DNA repair gene status in oesophageal cancer $R$ Naidoo, $T$ Chetty

\section{Papers}

131 Association of $\mathrm{p} 53$ genomic instability with the glutathione S-transferase null genotype in gastric cancer in the Portuguese population $A R$ Conde, G Martins, C Saraiva, $\mathcal{F}$ Rueff, C Monteiro

135 Absence of prolactin gene expression in colorectal cancer $A \mathcal{F}$ Wood, $C M$ Thomas, $K R$ N Baumforth, $\mathcal{f} R$ Flavell, $K W M$ Scott, $R H$ Grace, $f G$ Williams, $M R$ Holland, $R$ Dunn, $A$ G facobs, A Harrison, $S$ Brun, $N$ Plessis, P G Murray

140 Proteolysis in colorectal cancer $E A$ Garbett, $M W R$ Reed, $N \mathcal{F}$ Brown

146 Molecular detection of c-mpl thrombopoietin receptor gene expression in chronic myeloproliferative disorders $S$ Duensing, A Duensing, f G Meran, A Kreft, G Büsche, A Ganser, A Georgii

151 Alterations in cadherin and catenin expression during the biological progression of melanocytic tumours D $S A$ Sanders, K Blessing, $G A R$ Hassan, $R$ Bruton, $\mathcal{F} R$ Marsden, $\mathcal{F}$ Fankowski

\section{Technical reports}

158 Use of magnetic beads for tissue DNA extraction and IS6110 Mycobacterium tuberculosis PCR R Caldarelli-Stefano, L Vago, S Bonetto, M Nebuloni, $G$ Costanzi

160 A simple method for PCR based analyses of immunohistochemically stained, microdissected, formalin fixed, paraffin wax embedded material $H E$ Alcock, $T$ F Stephenson, $\mathcal{F}$ A Royds, $D$ W Hammond 